\title{
Characteristics of high blood pressure among postpartum hausa women in a specialist hospital in Nigeria
}

\begin{abstract}
Objective: The major aim of the study was to evaluate the prevalence of high blood pressure among postpartum Hausa women in Murtala Muhammad Specialist Hospital, Kano, Nigeria.

Method: A total of 150 postpartum women from Postnatal Clinic of MMSH participated in the study. The consent of the subjects was sought and subjects were recruited using Judgmental Sampling Technique. Subjects were included if they were between 2-6 weeks postpartum and were excluded if they were hypertensive before getting pregnant. The Height and Weight of the subjects was measured using a standard protocol and recorded. Blood pressure was measured at least twice during this period. Descriptive and Inferential Statistics was used to analyse and present the data. Probability level of 0.05 or less was considered in all analysis.
\end{abstract}

Results: The study revealed no relationship between age, BMI and hypertension. The prevalence of hypertension among the women during postpartum is higher $(76.7 \%)$ than during pregnancy.

Conclusion: There is a high percentage of women with hypertension during the postpartum period.

Keywords: prevalence, high blood pressure, post partum, hausa women
Volume 3 Issue 2 - 2018

\section{Farida Garba Sumaila, Aishat Shittu, Umamatu Muhammad Uwais, Jibrin Mohammed}

Department of Physiotherapy, Faculty of Allied Health Sciences, Bayero University Kano, Nigeria

\author{
Correspondence: Farida Garba Sumaila, Department of \\ Physiotherapy, Faculty of Allied Health Sciences, Bayero \\ University Kano, Nigeria, Tel +234 8036164228,07085769215 \\ Email fareedat2006@gmail.com \\ fgsumaila.pth@buk.edu.ng
}

Received: January 08, 2018 | Published: April 03, 2018

\section{Introduction}

Hypertension is a major public health problem in black populations worldwide. ${ }^{1,2}$ Although hypertension is usually asymptomatic, it may be associated with considerable morbidity and mortality. The higher the blood pressure, the greater the risk for adverse outcomes including development of coronary heart disease ${ }^{3}$. Hypertension treatment has been clearly shown to reduce this risk. ${ }^{3,4}$ A study conducted in Nigeria revealed $60 \%$ increase in the risk of death by every $20 \mathrm{mmHg}$ increase in diastolic blood pressure (DBP) and that $7 \%$ reduction in overall mortality would have been observed in the absence of hypertension. ${ }^{5}$

Obesity, especially regional fat distribution, is a known risk factor for hypertension. Several large epidemiological studies have shown an association between body mass index and blood pressure in normal weight and overweight patients. Weight gain in adult life especially seems to be an important risk factor for the development of hypertension. ${ }^{6}$

Prevalence of hypertension in Nigeria, the largest black nation, ranged from rates $8-10 \%$ in the rural setting to $10-12 \%$ for urban population. Hypertension may exist for prolonged periods in an individual without symptoms and may manifest only after causing serious irreversible pathology and complications. ${ }^{7}$ Stressful life events have been long associated with hypertension. ${ }^{8-10}$ However, awareness, treatment and control of hypertension remain major challenges worldwide. ${ }^{11}$ Hypertension can be prevented by complementary application and individuals and groups at higher risk for high blood pressure. $^{12}$

Having a higher blood pressure within normotensives limits in the second half of pregnancy is associated with reduced birth weight. ${ }^{13}$ Lowering a woman's blood pressure during pregnancy even in cases of mild hypertension may decrease the risk of perinatal mortality and abruption placentae..$^{14,15}$

A higher maternal age ${ }^{16}$ and lower gestational age at onset increase the risk of chronic hypertension. During the postnatal period, the hypertension and proteinuria due to pre-eclampsia and eclampsia resolve within six weeks, and women having persistent hypertension and proteinuria thereafter may have an underlying cause. Postnatal review at $2-6$ weeks after delivery provides an opportunity to ensure that manifestations of pre-eclampsia and any associated systemic complications have resolved. Early identification of chronic hypertension among women during follow-up might reduce/prevent its long-term complication. ${ }^{16}$

Although often controllable by pharmacotherapy ${ }^{17}$ many patients are unaware of the condition and thus are untreated, particularly among populations in transition. ${ }^{18}$ In Kano, information on the prevalence of hypertension among postpastum women is scarce, this study therefore sets out to evaluate the prevalence of postpartum hypertension among Hausa women in some selected hospitals in Kano State, Nigeria.

\section{Methodology}

The major purpose of this study was to determine the prevalence of postpartum hypertension among Hausa women in Murtala Muhammad Specialist Hospital (MMSH) Kano, Nigeria.

\section{Research design}

A descriptive survey research design was used in this study. 


\section{Population}

The population of this study comprised of postpartum women at the period of $2-6$ weeks postpartum attending postnatal clinic of MMSH.

\section{Sample size and sampling technique}

One hundred and fifty postpartum women were sampled using Judgmental sampling technique where only subjects that satisfy the inclusion/exclusion criteria would be recruited.
A. Inclusion criteria
i. Postpartum women between the period of 2-6 weeks postpartum
ii. Subjects with pregnancy induced hypertension (PIH)
iii. Subjects without PIH.

\section{B. Exclusion criteria}

i. Postpartum women below 2 weeks postpartum

ii. Postpartum women above 6 weeks postpartum

iii. Subjects that are hypertensive before getting pregnant

\section{Data collection instrument}

1. Stethoscope (Wenzhou Kangju Medical Devices Co. Ltd./S - 223 China) was used to measure blood pressure.

2. Mercury sphygmomanometer (Accoson/BS 2744/England). This was used to measure blood pressure.

3. Weighing scale- SECA salter 148BKSVDR China was used for measuring weight.

4. Height meter- This was used to measure height. ${ }^{19}$

\section{Data collection procedure}

Approval was sought from the ethical committee of the hospitals. The subjects were provided with information about the study. They were given consent form to fill and only those that filled the form were recruited. The postpartum period and age of the subjects was also noted. Also, their files were checked to see if they were hypertensive during pregnancy or not. The following measurements were taken:

\section{Blood pressure}

The blood pressure was monitored using a stethoscope and mercury sphygmomanometer. It was measured on the right arm after the subject had been sitting quietly for at least 5 minutes to relief anxiety, with her back supported, and cubital fossa at heart level. An inflatable cuff was wrapped around the arm and a stethoscope was placed over the brachial artery at the elbow. The cuff was rapidly inflated until the pressure in it was well above the expected systolic pressure in the brachial artery. The artery was then occluded by the cuff, and when no sound was heard with the stethoscope. The pressure in the cuff was then lowered slowly. The point at which a tapping sound was heard below the cuff is the systolic pressure. As the cuff pressure was lowered further, the sounds become louder, then dull and muffled, finally the sound disappeared, and the pressure at which the sound disappeared was the diastolic pressure. The cuff was then removed off the subject's arm and the blood pressure was recorded as systolic and diastolic blood pressures. Hypertension is defined as when the systolic and diastolic measurements on at least two subsequent occasions average $140 \mathrm{mmHg}$ and $90 \mathrm{mmHg}$ respectively.

\section{Stature}

The subject stood bare-footed; the upper back, buttocks and heels touched the wall, the head was held erect, and the eyes looked forward so that the lower margin of the external auditory canal opening was in frank-fort horizontal plane. The point of greatest height to the nearest $0.1 \mathrm{~cm}$ was marked off on the wall with flexible tape ${ }^{19}$.

\section{Body mass}

The weight was measured with the patient standing using a portable bathroom scale with provision for calibration. The weight was recorded to the nearest $0.5 \mathrm{~kg} .{ }^{19}$ Overweight was defined by a $\mathrm{BMI} \geq 30 \mathrm{Kg} / \mathrm{m}^{2}$.

\section{Body Mass Index (BMI)}

Subjects BMI was calculated as weight in kilogram/height in meter squares.

\section{Data analysis procedure}

Descriptive and Inferential Statistics was used to analyse and present the data. The mean and standard deviation was used to describe the data. Simple percentage was used to determine the prevalence of postpartum hypertension among Hausa women in MMSH. Pearson product moment correlation was used to determine the relationship between age and postpartum hypertension. Spearman rank order correlation was used to determine the relationship between BMI and postpartum hypertension. Mc Nemar was used in calculating the difference in the prevalence of hypertension during pregnancy and postpartum. Statistical Package for Social Sciences (SPSS) version 15.0 was used to analyze the data. Probability level of 0.05 or less was considered in all analysis.

\section{Result}

A total number of 150 subjects participated in this study.The result of the study showed that the mean age of the subjects was 26.82 . Main findings also showed that their average BMI to be 23.83, Height (1.56) and Body mass (57.44) as presented in Table 1. The result of the study also revealed a $76.7 \%$ prevalence rate of hypertension among postpartum subjects.

Table I Demographic characteristics of the subjects

\begin{tabular}{lll}
\hline Variables $(\mathbf{N}=150)$ & Mean \pm SD & Range \\
\hline Age $($ years $)$ & $26.82 \pm 7.317$ & $16-43$ \\
BMI $\left(\mathrm{Kg} / \mathrm{m}^{2}\right)$ & $23.83 \pm 5.72$ & $15.82-44.48$ \\
Stature $(\mathrm{m})$ & $1.56 \pm 0.099$ & $1.23-1.74$ \\
BM $(\mathrm{Kg})$ & $57.44 \pm 13.58$ & $40.0-125.0$ \\
\hline
\end{tabular}

Subjects were middle aged and averagely within the normal BMI range.

\section{Percentage of hypertensive subjects}

Percentage Rate $=$

Number of postpartum women with hypertension

$\overline{\text { Total population of postpartum women examined }}$ 
$=115 / 150$

$=0.767$ is

Therefore the percentage of postpartum women with hypertension

$$
0.767 \times 100
$$

\section{$=76.7 \%$}

Hypertension was prevalent in more than half of the study population (Table 2).

Table 2 Clinical characteristics of subjects $(N=\mid 50)$

\begin{tabular}{lcl}
\hline Variables & Mean \pm SD & Range \\
\hline $\mathrm{SBP}(\mathrm{mmHg})$ & $144.57 \pm 19.07$ & $100-190$ \\
$\mathrm{DBP}(\mathrm{mmHg})$ & $93.27 \pm 11.02$ & $60-120$
\end{tabular}

SB, systolic blood pressure; DBP, diastolic blood pressure

Both the relationship between age and hypertension (Pearson product moment correlation) and BMI and hypertension (Spearman rank order correlation) revealed no significant relationship $(\mathrm{P}>0.005)$ (Table 3).

Table 3 Relationship between age, BMI and hypertension

\begin{tabular}{lllll}
\hline & Variables & $\mathbf{r}$ & $\mathbf{p}$ & \\
\hline \multirow{2}{*}{ Age } & SHTN & 0.38 & 0.643 & \\
& DHTN & -0.015 & 0.852 & \\
& SHTN & 0.125 & 0.128 & \\
& DHTN & 0.049 & 0.55 & BMI
\end{tabular}

Table 4 showed a significant difference in the prevalence of hypertension during pregnancy and postpartum.

Table 4 Difference in the prevalence of Hypertension during pregnancy and postpartum $(\mathrm{N}=150)$

\begin{tabular}{lll}
\hline Variables & $\mathbf{X}^{2}$ & $\mathbf{P}$ \\
\hline SHTN (Pregnancy) & 25.412 & 0 \\
SHTN (Postpartum) & & \\
DHTN (Pregnancy) & & \\
DHTN (Postpartum) & 23.814 & 0
\end{tabular}

\section{Discussion}

An elevated arterial pressure is probably the most important public health problem in developed as well as developing countries. It is common, readily detectable, usually easily treatable, and often leads to lethal complications if left untreated. ${ }^{20}$

Age was found not to be related to blood pressure in this study and this is not in line with those reported by other studies. ${ }^{21,22}$ Also in this study it was found out that there is no relationship between BMI and hypertension as this is in contrast to what a reported which showed that weight gain is associated with increased BP and increased hypertension. ${ }^{6}$ This trend may be due to the fact that all of the subjects in this study are within the child bearing age (15-45 years) which is not likely to be a risk age group for hypertension.
Maternal hypertension and proteinuria will usually resolve during the first week postpartum in most women with gestational hypertension or pre-eclampsia. ${ }^{23-26}$ This is in contrast to what is obtained in this study because more than $70 \%$ of the subjects were still hypertensive after the the first week postpartum.

This study showed age and BMI does not have any effect on postpartum hypertension and more than half of the subjects were hypertensive.

\section{Conclusion}

The study concluded that a large number of postpartum women have hypertension. Age and BMI does not affect both systolic and diastolic hypertension of the postpartum women.

\section{Recommendation}

Education and more enlightenment campaign should be intensified to postpartum women to change the current rate.Regular/routine measurement of BP by health care providers is important in detecting high blood pressure during pregnancy. This will help in early control and prevention of its occurrence during postpartum.

\section{Acknowledgments}

None.

\section{Conflict of interest}

The author declares no conflict of interest.

\section{References}

1. Akinkugbe OO, Nicholson GD. Cruickshank JK. Heart disease in blacks of Africa and the Carribean. Cardiovasc Clin. 1991; 21:377-391.

2. Cooper R. Rotimi C, Ataman S, et al. The prevalence of hypertension in seven populations of West African Origin. Am J Public Health. 1997; $87: 160-168$

3. Lewington S, Clarke R, Qizibash N, et al. Age-specific relevance of usual blood pressure to vascular mortality: a mental-analysis of individual data for one million adults in 61 prospective. Lancet. 2002;360:1903-1913.

4. Collins R, Peto R, Macmahon S, et al. Blood pressure, stroke and coronary heart disease part 2, short-term reductions in blood pressure: overview of randomnised drug trials in their epidemiological context. Lancet. 1990;335:827-838.

5. Kaufman JS, Rotimi CN, brieger WR, et al. The Mortality Risk Associated with HTN: Preliminary Results of a Prospective Study in Rural Nigeria. Journal of Human hypertension. 1996;10(7):461-64.

6. Musa DI, Uzonicha JO, Dikko AU. The Role of Physical Exercise in theManagement of Hypertension. Journal of Research in Health and Sport Science. 2003;5(1):17-26.

7. Hamadah FA, Akanani LM. Al-Ajmi SS, et al. Prevalence of undiagnosed HTN among apparently healthy subjects in Kuwait. Bulletin of Alexandria, faculty of Medicine. 2009;45(3):619-624.

8. Nyklicek I, Vingerhoets JJ, Van Hee GL. Hypertension and Objectives and Self-reported Stressor exposure: a review. J Psychom Res. 1996;40:585601 .

9. Parati G, Antonicelli R, Guazzarotti F, et al. (cardiovascular Effects of an Earthquake). Direct evidence by ambulatory blood pressure monitoring. Hypertension. 2001;38:1093-1095.

10. Schwartz AR, Gerin W, Davinson KW, et al. Towards casual model of 
cardiovascular responses to stress and the development of cardiovascular diseases. Psychosom Med. 2003;65:22-35.

11. Khader SA, Vasamn R, Sarma PS, et al. Prevalence - Correlates awareness treatment and control of HTN in Kamarakom Kerata: Baseline results of a community-based Intervention Program. Indian Heart J. 2006;58(1):28-33.

12. Whelton PK. Epidemiology of hypertension. Lancet. 1994;344:692-98.

13. Churchill D, Perry IJ, Beevers DG. Ambulatory blood pressure in pregnancy and foetal growth. Lancet. 1997;349:7-10.

14. Von Dadelszen P, Ornstein MP, Bull SB, et al. Fall in mean arterial pressure and foetal growth. Lancet. 2001;355(9198):87-92.

15. Ferrer RL, Sibai BM, Mulrow CD, et al. Management of mildchronic hypertension during pregnancy: a review. Obstet gynecol. 2000;96(5 pt 2):849-60.

16. Chandramani M, Waugh J, Shenan AH. Management of hypertension and pre-eclampsia in pregnancy. Trends urol Gynaecology sex Health. 2007;12(3):23-8.

17. Berlowitz DR. Ash AS, Hickey EC, et al. Inadequate Management of blood pressure in a hypertensive population. N Engl Jmed. 1998;339(27):19571963.

18. Zachariah MG, Thankappan KR, Alex SC, et al. Prevalence, correlates, awareness, treatment and control of HTN in a middle-aged urban population in Kerala. Indian heart Journal. 2003;55(3):245-51.

19. Musa DI, Ismaila S, Mohammed R. Age-related Differences in Anaerobic
Power of Female University Students. Africa Journal for Physical health Education. Recreationand Dance. 2003;9(4):10-11.

20. Akinpelu AO. Beneficial Effects of Exercise in the Management of Hypertension. Physiotherapy Journal. 1990;28-30.

21. Grandelman G. Essential hypertension. Philadelphia: W.B. Saunders; 2005.

22. Peterson E, Craigo SM, House M. Risk Factors for postpartum Antihypertensive Medication requirement in severe pre-eclampsia. Hypertens Pregnancy. 2010;29(3):350-6.

23. Walters BM, Walters T. Hypertension in the puerperium. Lancet. $1987 ; 2: 330$.

24. Ferrazzani S, Decardis SM, Pomini F, et al. The duration of hypertension in the puerperium of pre-eclamptic women: relationship with renal impairment and week of delivery. Am J Obstet Gynecol. 1994;171(2):50612.

25. Staphan H, Nordmeyer A, Faber R. Protein in hypertensive pregnancy diseases is associated with longer persistent hypertension postpartum. $J$ Hum Hypertens. 2006;20(2):125-8.

26. Schiff E, Friedman SA, kao L, et al. The importance of urinary protein excretion during conservative management of severe pre-eclampsia. Am J Obstet Gynecol. 1996;175(5):1313-6. 